\title{
Autoamputation of diabetic toe with dry gangrene: a myth or a fact?
}

This article was published in the following Dove Press journal: Diabetes, Metabolic Syndrome and Obesity:Targets and Therapy

\author{
Abdullah Al Wahbi \\ Division of Vascular Surgery, King \\ Abdulaziz Medical City, Riyadh, Saudi \\ Arabia
}

\begin{abstract}
Diabetes is associated with various complications and reduced quality of life. Of the many complications, some are life-threatening. Among these, foot complications remain an important concern. The major foot complications include foot ulceration, cellulitis, abscess, wet gangrene, dry gangrene, and necrotizing fasciitis, with different pathophysiological concepts behind each of them. Gangrene occurs due to reduced blood supply in the body tissues that leads to necrosis. This condition may arise because of an injury, infection, or other health conditions, majorly diabetes. Gangrene is classified as dry, wet, and gas gangrene. In case of wet and gas gangrene, surgical amputation is usually performed to prevent the spread of infection to other tissues. In dry gangrene, due to the presence of clear demarcation, autoamputation is preferred in certain parts of the globe. The present review aims to analyze the mode of dry gangrene management in diabetic patients based on previous evidence and plans to highlight various management strategies available for dry gangrene and the advantages/disadvantages of different treatments with special consideration to autoamputation.
\end{abstract}

Keywords: dry gangrene, amputation, surgical amputation, diabetic foot, diabetic toe, foot care.

\section{Introduction}

Diabetes occurs due to impairment in either pancreatic production of insulin or utilization of the produced insulin. ${ }^{1}$ It is one of the leading causes of deaths worldwide, the other causes being acquired immune deficiency syndrome, malaria, and tuberculosis. ${ }^{2}$ With time, the worldwide prevalence of diabetes has increased more in the developing countries than in the developed ones. The global diabetes burden has increased from $4.7 \%$ in 1980 to $8.5 \%$ in $2014 .^{1}$ The Gulf countries including Saudi Arabia, Kuwait, and Qatar, along with the North African countries have the second highest number of diabetics globally. With this trend, the number of diabetics in the Middle East and North African region is expected to increase by $96.2 \%$ in the next 17 years. The disease along with its associated complications has placed the Arab governments under a huge economic burden. ${ }^{3}$

Diabetes is associated with various complications and reduced quality of life (QoL). Of the many complications, some are life-threatening. Among these, foot complications remain an important concern. The major foot complications include foot ulceration, cellulitis, abscess, wet gangrene, dry gangrene, and necrotizing fasciitis, with different pathophysiological concepts behind each of them. ${ }^{4}$ As per the World Health Organization, there are always higher chances of limb amputation among diabetic patients as compared to non-diabetics. ${ }^{1}$ Amputation may lead to longer hospital stay, increased
Correspondence: Abdullah AI Wahbi Division of Vascular Surgery, King Abdulaziz Medical City, P.O. Box 22490, Riyadh I I426, Saudi Arabia Tel +966011801 IIII ext I5484 Fax +9660118015700 Email wahbia@ngha.med.sa 
deaths, and reduced rehabilitation. As per a retrospective study conducted by Badri et al on 222 patients with a total of 252 amputations, the percentage of patients who were hospitalized for $>10$ days post-amputation ranged between $50 \%$ (for those who underwent one toe amputation) and $91 \%$ (for those who underwent above-knee amputation). Also, $57.1 \%$ of patients with post-surgical complications faced longer hospitalization of more than a month as compared to patients who did not have any post-surgical complications (16.8\%). Early deaths were reported in 16 patients $(7.2 \%)$ who had faced autoamputation. Only $8.8 \%$ of patients were rehabilitated after major amputations and had undergone artificial limb fitting. ${ }^{5}$

As per analysis of two studies done by Alzahrani, the number of amputations is likely to be 741 in Riyadh, the capital of Saudi Arabia, and 3970 for the whole country. As per reports, the estimated number of amputations in Saudi Arabia is 1647 yearly. As per the International Diabetes Federation, the number of diabetics is increasing in the Middle East countries, with high pervasiveness in the Kingdom of Saudi Arabia (20\%), Kuwait (21.1\%), Lebanon (20.2\%), Bahrain (19.9\%), and the United Arab Emirates (19.2\%), thus leading to more amputation rates. ${ }^{6}$ Various risk factors affecting the diabetic foot complications include peripheral neuropathy, peripheral vascular disease, duration of diabetes, foot deformity, previous foot ulceration, and long-term hyperglycemia. ${ }^{7}$ The major causes for the diabetic foot complications in the Middle East countries include poverty, lack of education, unhygienic living environment, and religious and cultural traditions. Apart from medical treatment, educating people about diabetes, diabetes control, and foot care should be considered important to overcome these challenges. ${ }^{8}$

In dry gangrene, due to the presence of clear demarcation, autoamputation concept is widely followed. ${ }^{9}$ However, waiting for the affected limb to auto-amputation may increase the discomfort for the patient, in addition to other health challenges. Many reports have shown that surgically amputating the dry gangrene limb relieves patients and improves their QoL with better outcomes. ${ }^{10}$

Although several management strategies are available, autoamputation is practiced in certain parts of the globe. In this scenario, the present review aims to analyze the mode of dry gangrene management in diabetic patients based on previous evidence and plans to highlight various management strategies available for dry gangrene and the advantages/disadvantages of different treatments with special consideration to autoamputation.

\section{Methodology Electronic databases searched}

Various articles were searched using search engines including PubMed, EMBASE, Cochrane database, and the World Health Organization website. Manual searches of bibliographies were also done. Filters of each heading included in the review were applied separately. Major focus was on diabetesassociated gangrene and amputation in the Arab population.

\section{Inclusion and exclusion criteria}

All original research articles, case studies, and case reports stating information about gangrene and amputation in diabetes patients, both globally and in special reference to Middle East countries were included. Animal studies and studies not in context with diabetes-associated gangrene and amputation were excluded. Also, studies with a focus on amputation of body parts other than limbs were excluded.

\section{Search terms}

The search terms were: Diabetes, Diabetic foot, Gangrene, Amputation, Autoamputation, Middle East, Gulf, Saudi Arabia, Foot care.

The abstracts, conclusions, and discussions of all the studies were studied to finalize the articles to be included.

\section{Gangrene: an overview}

Gangrene occurs due to reduced blood supply in the body tissues that leads to necrosis. This condition may arise because of an injury, infection, or other health conditions, majorly diabetes. Gangrene is classified as dry, wet, and gas gangrene $^{11}$ (Table 1).

\section{Dry gangrene}

Dry gangrene is a condition that involves tissue death and turns it dry, dark, and mummified due to arterial occlusion. It takes place gradually, progresses slowly, and affects the lower extremities of the body (toes and feet) due to insufficient blood supply to the tissues. Dry gangrene is very common in individuals suffering from arteriosclerosis, high cholesterol, diabetes, and smoking. ${ }^{11}$ As per the International Diabetes Federation global report in 2015, 9.1-26.1 million people with diabetes develop foot ulcers, which may further lead to gangrene. ${ }^{12}$ In dry gangrene, due to necrosis, the tissue becomes shrunken and blackened and gets detached._In this condition, autoamputation is usually practiced due to occurrence of clear lines of demarcation. If dry gangrene is left untreated or 
Table I Differences in features of dry gangrene, wet gangrene, and gas gangrene

\begin{tabular}{|c|c|c|c|}
\hline Feature & Dry gangrene & Wet gangrene & Gas gangrene \\
\hline Site & Commonly limbs & More common in bowel & Limbs \\
\hline Mechanism & Arterial occlusion & More commonly venous obstruction & Gases produced by Clostridium bacteria \\
\hline Macroscopy & Organ dry, shrunken, and black & $\begin{array}{l}\text { Part moist, soft, swollen, rotten, and } \\
\text { dark }\end{array}$ & $\begin{array}{l}\text { Organ red, cold, pale, numb, shriveled up, } \\
\text { and auto-amputation }\end{array}$ \\
\hline Putrefaction & Limited due to very little blood supply & $\begin{array}{l}\text { Marked due to congestion of organ } \\
\text { with blood }\end{array}$ & $\begin{array}{l}\text { Marked due to bacteria and infiltration of } \\
\text { gases produced by them in tissues }\end{array}$ \\
\hline $\begin{array}{l}\text { Line of } \\
\text { demarcation }\end{array}$ & $\begin{array}{l}\text { Present at the junction between healthy } \\
\text { and gangrenous parts }\end{array}$ & No clear-cut line of demarcation & No clear-cut line of demarcation \\
\hline Bacteria & Bacteria fail to survive & Numerous present & Major cause \\
\hline Prognosis & Generally better due to little septicemia & $\begin{array}{l}\text { Generally poor due to profound } \\
\text { toxemia }\end{array}$ & $\begin{array}{l}\text { Generally poor due to quick spread to the } \\
\text { surrounding tissues }\end{array}$ \\
\hline
\end{tabular}

Note: Data from NHP.gov.in. ${ }^{\prime \prime}$

treatment is delayed, it may progress to cause infections and complicate the condition. Following autoamputation practice also increases the painful phase and decreases the QoL. ${ }^{9}$

\section{Wet gangrene}

Wet or moist gangrene is a condition that occurs due to compromised or immobile venous and/or arterial blood, which leads to bacterial infection or sepsis. It mainly affects the body tissues which are naturally moist (oral tissues, respiratory tissues, cervix, and vulva). Diabetics are always at a high risk of compromised skin integrity and impaired wound healing due to peripheral neuropathy, vascular insufficiency, and hyperglycemia. Thus, being infection prone, diabetic patients are very susceptible to wet gangrene condition. As wet gangrene spreads quickly and can be fatal, prompt treatment is preferred. ${ }^{11,13}$ In case of wet gangrene, surgical amputation is usually performed to prevent the spread of infection to other tissues. ${ }^{14}$

\section{Gas gangrene}

Gas gangrene is a life-threatening infection where presence of gas at the infection site turns the tissue pale, bronze to purplish-red with development of multiple hemorrhagic bullae. Gas gangrene occurs in various clinical settings and can be classified as posttraumatic, postoperative, and spontaneous types. Spontaneous type of gas gangrene occurs in patients with any underlying conditions, majorly diabetes mellitus. It is a quickly spreading condition which involves the production of gas due to bacterial infection caused by Clostridium perfringens. An early identification and therapy with radical amputation is the best treatment of choice. ${ }^{11,15}$

\section{Factors contributing to diabetes and associated dry gangrene}

There are various factors that contribute to the occurrence and high prevalence of dry gangrene in diabetic patients.
The factors commonly causing dry gangrene in diabetics are mentioned below.

\section{Lifestyle}

With modernization, the Gulf countries are nowhere lagging in following urban lifestyle. High-calorie foods, relying on technology, and sedentary lifestyle have contributed to an increase in the numbers of diabetics and obese patients in the Middle Eastern world. Adapting to a healthy lifestyle is the best way to reduce the risk of gangrene occurrence among diabetics. This includes consuming healthy diet and practicing regular exercise. ${ }^{16}$

\section{Age/gender}

The prevalence of diabetes-associated foot complications is directly proportional to advancing age. As per a retrospective cohort study conducted by Al-Rubeaan et al, rates of foot ulcers were reported to increase with age, with higher rates found $(4.2 \%)$ for males aged $\geq 75$ years and females aged between 65 and 74 years $(2.5 \%) .{ }^{17}$

\section{Foot care and habits}

Diabetic patients are always at a high risk of developing foot complications. Wearing tight shoes, walking barefoot, and poor control over diabetes give access to foot complications. Hence, proper foot care and managing daily habits are mandatory. ${ }^{18}$

\section{Education}

Lack of education is another major factor that contributes to diabetic foot complications. As per a survey study by Nemcová and Hlinková, educating people to control obesity and blood pressure, and on foot care has shown positive effects on disease. ${ }^{19}$ Another hospital-based, cross-sectional study conducted in Saudi Arabia by Odhayani et al showed 
that having little or no knowledge about the risk factors, future complications, and foot care in diabetes worsen the condition. $^{20}$

Other factors that may contribute to diabetic dry gangrene include climate, weather conditions, and following various religious and cultural beliefs. ${ }^{21-23}$

\section{Pathophysiological factors in dry gangrene}

There are different pathways involved in the pathophysiology of dry gangrene (Figure 1). These include various metabolic, vascular, and neuropathy factors. ${ }^{24}$

\section{Metabolic factors}

Diabetes and obesity are the two main metabolic diseases. Hence, hemoglobin A1c and body mass index are directly proportional to the occurrence of gangrene condition. Poor glycemic control and obesity contribute to microvascular angiopathy and increased pressure on foot, respectively. Thus, these factors should be critically considered while treating gangrene patients. As per a prospective analytical study conducted by AlGoblan et al, ${ }^{25}$ early resolution of the foot ulcers occurred in $61 \%$ patients who were a normal weight, compared to $49 \%$ obese patients whose condition took more than double the time to resolve. ${ }^{26}$

\section{Vascular factors}

Vascular system plays an important role in the etiology of dry gangrene. Peripheral arterial disease/arteriosclerosis involves shrinking of the peripheral arteries, majority of which supply the lower extremities. It is mainly associated with ischemic claudication, which involves pain and cramps due to decreased blood supply to the tissues. Thus, the major culprit behind dry gangrene is ischemia. When chronic ischemia is worsened, it causes critical limb ischemia, which further results in discoloration, numbness, dryness, and necrosis of the affected part. ${ }^{11,27,28}$

\section{Neuropathy factors}

Patients with diabetic peripheral neuropathy are highly susceptible to foot complications, including gangrene and amputations. As per a large cohort study by Al-Rubeaan et al, diabetic patients usually face nerve compression in the lower limbs. Thus, examination and surgical decompression of the nerve should be considered. This helps in increasing the microcirculation as well as overall nerve function in the limbs. ${ }^{17}$

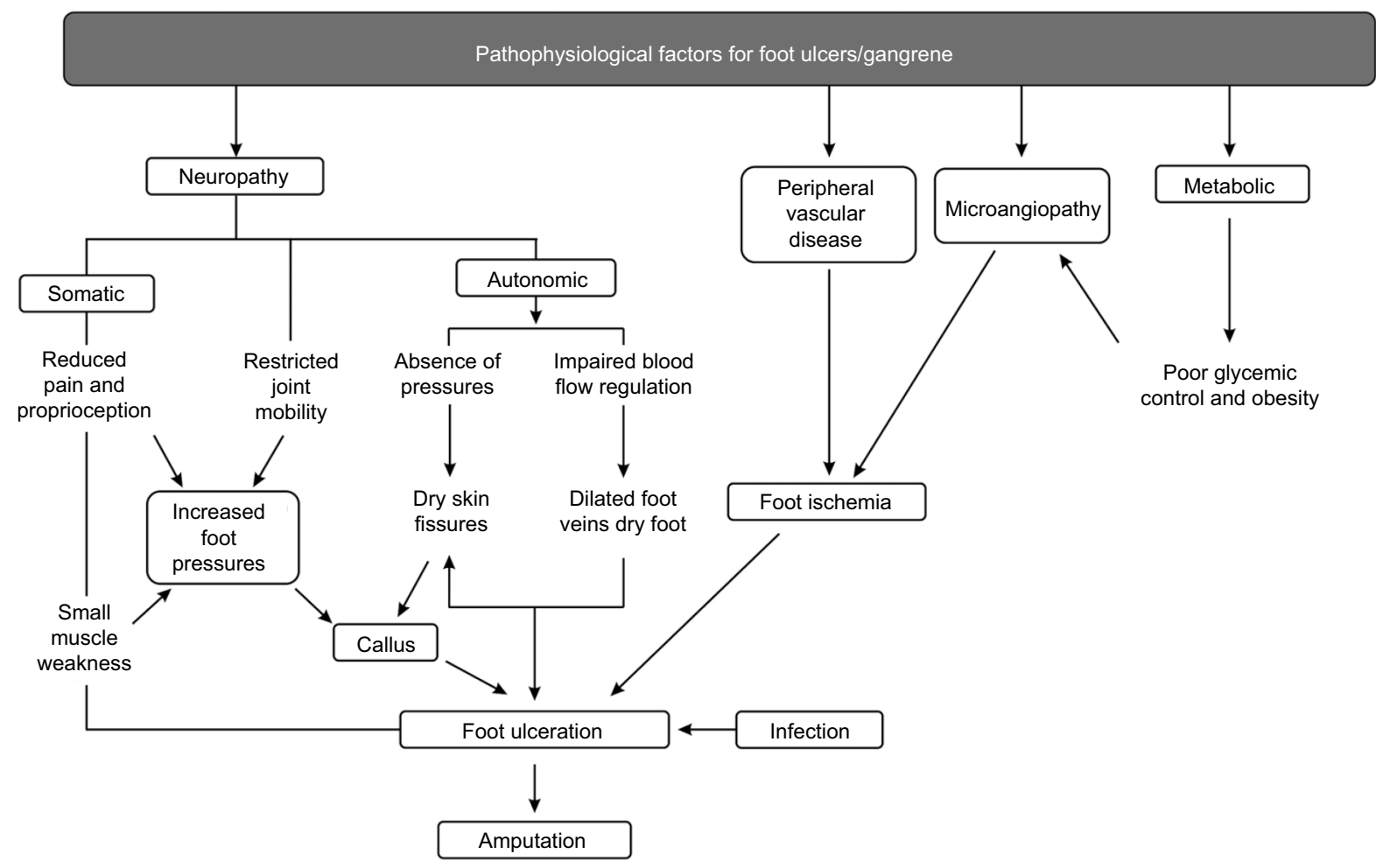

Figure I The pathophysiological pathways of dry gangrene

Note: Adapted from: Rodrigues J, Mitta N. ${ }^{24}$ 


\section{Autoamputation in dry gangrene among diabetics}

Autoamputation is the self-detachment of nonviable tissue from viable tissue. In dry gangrene, autoamputation is very commonly preferred, mainly in patients who are not good candidates for surgery. Due to nerve damage and reduced blood circulation to the extremities, foot ulcers and slow healing wounds occur, which further causes limb detachment. It is generally practiced for the distal portions of the affected limbs by leaving an intact tissue eschar. The risk of amputation in diabetes patients is around $>25$ times as compared to that in non-diabetics. The process of autoamputation may take several months and is a very uncomfortable phase. Thus, a long wait may make the condition worsen with increased pain and reduces the QoL in patients. ${ }^{9,29,30,31}$ Thus, an early diagnosis and treatment of dry gangrene should be considered very critical.

\section{Management of dry gangrene}

Before starting any treatment, it is important to diagnose the type and extent of gangrene. Diagnosis of gangrene starts with documentation of patient's history, physical examination, blood tests, and other investigations. Information regarding chronic diseases, surgeries, smoking, and exposure to extremely cold conditions is needed for the diagnosis. Various tests and investigations can be carried out to confirm the diagnosis of gangrene. These include the following:

- Physical examination of the affected body part and blood tests to identify infection.

- Drainage sample collection or tissue culture is done to know the bacteria responsible for infection.

- Imaging tests such as X-ray, magnetic resonance imaging, and computerized tomography are performed to confirm the spread of gangrene and the extent of damage caused to the tissues. These scans also help in detecting the presence of blockages in blood vessels. ${ }^{32}$

Dry gangrene can very easily turn into wet gangrene causing wounds and related complications. Thus, the first step in treatment is to optimally manage wound care, especially those that originate from gangrene. ${ }^{33}$ Wounds associated with diabetic foot amputation are very critical, especially in patients with poor immunity. ${ }^{34}$ Hence, depending on the nature and type of wound, selection of an appropriate strategy for therapy depending on patient's condition. ${ }^{35}$

Treatment of dry gangrene may be done through pharmacologic and nonpharmacologic strategies as appropriate.

\section{Pharmacologic approach}

Pharmacologic approach for the treatment of dry gangrene in diabetics involves management of different pathways that may worsen the patient's condition (Table 2). This section elaborates the various strategies employed..$^{36-38}$

\section{Diabetes management}

Poor glycemic control is one of the common factors responsible for causing or aggravating foot condition in diabetics. Thus, diabetes patients exhibit 15 times more chances of amputation than non-diabetics. ${ }^{39,40}$ Since diabetes is a metabolic disease, lifestyle changes positively impact patient's health. Additionally, pharmacologic management is required with the intervention of antidiabetic agents. These drugs are selected depending on the patient's condition, type/severity of diabetes, age, and other factors. Treatment of type 2 diabetes mellitus is recommended, either when glycemic control is not attained or when hemoglobin A1c increases to $>6.5 \%$ in $2-3$ months after incorporating lifestyle changes. ${ }^{41}$

A good glycemic control is required in diabetes patients to avoid future complications. ${ }^{39}$ Qari and Akbar reported in their retrospective study on Arabs that $59 \%$ of diabetes patients suffered from foot ulcers. Of these, $65 \%$ patients required debridement and $23.5 \%$ patients underwent limb amputation. Others had good glycemic control with oral hypoglycemic agents and insulin. ${ }^{40}$

Another retrospective cohort study by Schellhase et al demonstrated that a good glycemic control in type 2 diabetes patients decreases the chances of microvascular complications. This further prevents occurrence or aggravation of limb ulcers, gangrene, and amputations. ${ }^{42}$

\section{Pain management}

Gangrene is usually associated with intermittent claudication in the limbs of patients. Thus, it is important to effectively manage the pain to let patient continue exercises to improve circulation. Opioid analgesics are recommended for pain associated with chronic limb ischemia. Apart from vascular factors, neuropathic pain should also be managed as a priority. ${ }^{43}$

\section{Circulation management}

As the senile/dry gangrene is a consequence of ischemia, improving the blood circulation in limbs helps overcome peripheral artery disease. ${ }^{43}$ As per the American Diabetes Association, antiplatelet therapy or platelet aggregation 
Table 2 Pharmacologic approaches for gangrene management

\begin{tabular}{|c|c|c|}
\hline $\begin{array}{l}\text { Pharmacologic } \\
\text { approach }\end{array}$ & Drugs class examples & Mechanism of action \\
\hline \multirow[t]{2}{*}{ Pain management } & $\begin{array}{l}\text { Opioids and opioid-like analgesics } \\
\text { Morphine, oxycodone, dextromethorphan, } \\
\text { tapentadol, tramadol }\end{array}$ & $\begin{array}{l}\text { Mimic the actions of endogenous opioid peptides by interacting with mu, } \\
\text { delta, or kappa opioid receptors }\end{array}$ \\
\hline & Topical medications: capsaicin, lidocaine & Provide local action on the skin to relieve pain \\
\hline \multirow[t]{3}{*}{$\begin{array}{l}\text { Circulation } \\
\text { management }\end{array}$} & $\begin{array}{l}\text { Antiplatelet agents: aspirin, clopidogrel, } \\
\text { prasugrel, ticlopidine, dipyridamole, abciximab, } \\
\text { eptifibatide, tirofiban, ticagrelor, vorapaxar }\end{array}$ & Prevent the aggregation of platelets and fibrinogenesis \\
\hline & $\begin{array}{l}\text { Anticoagulants: heparin, fondaparinux, } \\
\text { danaparoid, bishydroxycoumarin, warfarin, } \\
\text { acenocoumarol, phenindione }\end{array}$ & $\begin{array}{l}\text { Cause activation of anticlotting factors, direct inhibition of thrombin, } \\
\text { inhibition of synthesis of blood coagulation factor precursors (zymogens), and } \\
\text { activation of protein C }\end{array}$ \\
\hline & $\begin{array}{l}\text { Fibrinolytic agents: streptokinase, urokinase, } \\
\text { alteplase, reteplase, tenecteplase }\end{array}$ & Cause lysis of thrombi/clot to recanalize the occluded vessels \\
\hline \multirow[t]{8}{*}{ Antibiotics } & Penicillins: flucloxacillin & $\begin{array}{l}\text { Inhibit bacterial cell wall synthesis by binding to specific penicillin-binding } \\
\text { proteins located inside the bacterial cell wall }\end{array}$ \\
\hline & Fluoroquinones: ciprofloxacin & $\begin{array}{l}\text { Inhibit topoisomerase II (DNA gyrase) and topoisomerase IV, which } \\
\text { are required for bacterial DNA replication, transcription, repair, strand } \\
\text { supercoiling repair, and recombination }\end{array}$ \\
\hline & Antiprotozoals: metronidazole & $\begin{array}{l}\text { In reduced form, they covalently bind to DNA, disrupt its helix structure, } \\
\text { inhibit bacterial nucleic acid synthesis, and cause bacterial cell death }\end{array}$ \\
\hline & Carbapenems: ertapenem, meropenem & Show bactericidal activity by inhibiting the bacterial cell wall synthesis \\
\hline & Glycopeptides: teicoplanin, vancomycin & Inhibit the bacterial cell wall synthesis and cause cell death \\
\hline & Tetracyclines: doxycycline & $\begin{array}{l}\text { Reversibly bind to } 30 \text { ribosomal subunits and possibly to } 50 \text { s subunits, } \\
\text { block the binding of aminoacyl tRNA to mRNA, and inhibit bacterial protein } \\
\text { synthesis }\end{array}$ \\
\hline & Lincosamides: clindamycin & $\begin{array}{l}\text { Inhibit bacterial protein synthesis by binding to } 50 \text { S ribosomal subunits of the } \\
\text { bacteria }\end{array}$ \\
\hline & Oxazolidinones: linezolid & $\begin{array}{l}\text { Selectively inhibit bacterial protein synthesis by binding to bacterial ribosomes } \\
\text { and prevent the formation of a functional } 70 \mathrm{~S} \text { initiation complex }\end{array}$ \\
\hline
\end{tabular}

Note: Data taken from Tripathi, ${ }^{36} \mathrm{NHS} .{ }^{\circ},{ }^{3 .}{ }^{37}$ and Drugbank.ca. ${ }^{38}$

inhibitors are highly recommended for preventing the vascular complications in diabetes patients. ${ }^{44}$ Apart from drugs, in dry gangrene patients with peripheral arterial disease, guideline-directed management and therapy should be followed to decrease arterial occlusion or impaired perfusion, prevent the progression of chronic critical limb ischemia, and improve the functional status of affected limbs. This involves exercises which are done under structured or unstructured programs. Structured exercise programs include intermittent walking followed by alternate rest time. These are organized in the health care facilities and are supervised by a trained health care professional. Unstructured home-based exercise programs also include walking as a major exercise without any supervisor's guidance. ${ }^{43,45}$

Massage therapy is also recommended to improve the circulation in limbs. Only light pressure massage is given to the affected limb to avoid any clot formation. Massage should be cautiously done in patients with stent, with special instructions given by the health care professional. ${ }^{46}$

\section{Lipid-lowering agents}

Dyslipidemia plays a major role in the progression of diabetic toe gangrene. Thus, diabetes patients should undergo a regular lipid profile check-up. In a descriptive case series study performed by Memon et al, 55.11\% cases were reported to have abnormal lipid profile and $44.89 \%$ cases had lipid profile within the normal range. As per Wagner's scale, the percentage of patients with superficial ulcers (Grade I), ulcer extension (Grade II), deep ulcer with abscess (Grade III), gangrene of ore foot (Grade IV), and extensive gangrene foot (Grade V) was found to be $30.61 \%, 19.39 \%$, $21.42 \%, 16.33 \%$, and $12.25 \%$ respectively. Significant difference $(p=0.001)$ was found in gangrenous diabetic foot, grade IV and grade $\mathrm{V}^{47}$

Along with making lifestyle changes, diabetes patients with dyslipidemia should also consume lipid-lowering agents. Usually, statins or 3-hydroxy-3-methyl-glutaryl-CoA reductase inhibitors are considered to lower the bad cholesterol or low-density lipoproteins. There are various statins, and they 
have been reported to show a dip in low-density lipoprotein profile by $20 \%-40 \%{ }^{48}$

\section{Surgical procedures}

In dry gangrene, people wait for autoamputation to happen, either due to cultural beliefs or just as an option/alternative to surgery. ${ }^{49}$ Before any surgical decision, dry gangrene patients should be examined and treated for peripheral vascular disease. This includes reperfusion in the affected extremity for quick healing of the area affected by gangrene. ${ }^{50}$ Vascular surgeons perform various vascular examinations which include angiogram, ankle-brachial index test, carotid duplex, computed tomography angiography/magnetic resonance angiography tests, and duplex ultrasound. ${ }^{51}$

\section{Angiogram}

Angiogram is a diagnostic as well as a therapeutic procedure that involves the use of X-rays to know about the obstruction in arteries. This helps the vascular surgeons to take decisions about treatment to be provided. Angioplasty and stenting are mainly used to open the blocked or narrow vessels. ${ }^{51}$

\section{Ankle-brachial index test}

This test helps in determining arterial blood circulation and blood pressure in the lower extremities. ${ }^{51}$

\section{Carotid duplex test}

This test is done to know the rate of blood flow through carotid arteries. It helps in exploring the presence of any plaques that may cause carotid artery disease..$^{51}$

\section{Computed tomography angiography and magnetic resonance angiography}

These are the computerized imaging tests that are useful in studying in the blood vessels. These techniques help the vascular surgeons to know the severity of disease..$^{51}$

\section{Duplex ultrasound}

Duplex ultrasound is used to assess the blood flow status in blood vessels. With this technique, vascular surgeons easily explore existence of any occlusion or clot and plan the treatment. ${ }^{51}$

\section{Skin perfusion pressure (SPP) and skin vascular resistance}

SPP and skin vascular resistance measurements also help in distinguishing the patients who require vascular reconstruction or major amputation and the patients who only require foot care or require minor amputation (Figure 2). A prospective, double-blinded study by Castronuovo et al concluded that in $\sim 80 \%$ cases, SPP helps in diagnosing the critical limb

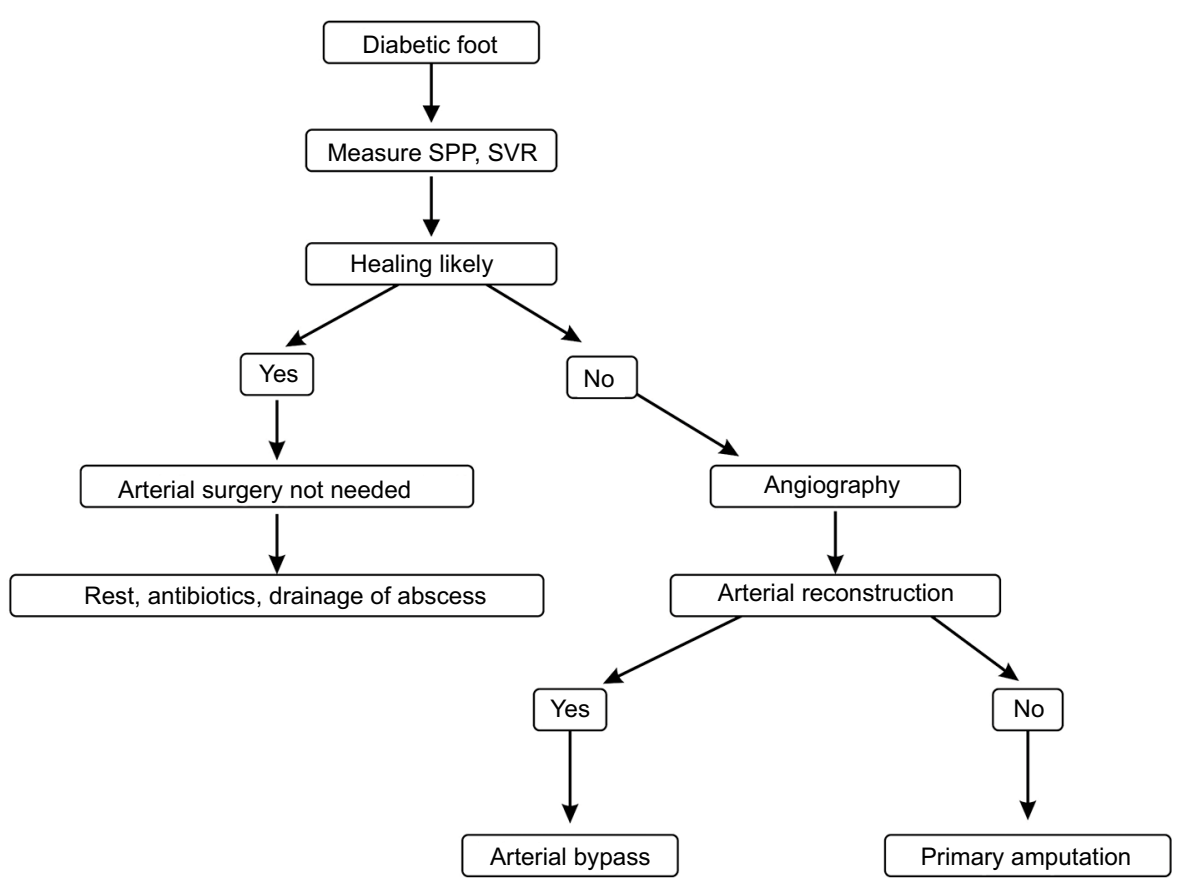

Figure 2 Management of dry gangrene.

Note: Adapted from: Rodrigues J, Mitta N. ${ }^{24}$

Abbreviations: SPP, skin perfusion pressure; SVR, skin vascular resistance. 
ischemia accurately. ${ }^{24,52}$ Thus, the management of diabetic gangrene should be individualized, taking all these factors into consideration.

\section{Shellac}

Shellac, a natural agent, is used as a part of complementary and alternative medicine. This approach is practiced in Arabic-speaking countries and in people who refuse to undergo surgical amputation. Shellac helps by acting as a shield to protect the gangrene tissues from further infections. As per a randomized, controlled, pilot study conducted by Alzahrani et al, the rate of amputation was found to be lower (46.2\%) in Shellac-treated type 2 diabetes mellitus patients than in $10 \%$ povidone-iodine-treated group $(60 \%))^{53}$

\section{Nonpharmacologic approach Education/foot care}

Implementation of proper guidelines and educating people are essential to reduce the burden of diabetic foot complications. A quantitative research study conducted by John showed that $33 \%$ of diabetes patients had average knowledge, $1.66 \%$ had poor knowledge, and the rest had good knowledge about foot care. ${ }^{49}$ In Gulf countries, the knowledge about foot care in diabetics is lacking, especially in rural areas. ${ }^{3}$ Hence, educational programs should be regularly conducted in hospitals and other health care institutions to increase awareness among the Arabian population. ${ }^{23}$

Apart from medicines, it is important to inculcate the basic foot care habits in people. Patients should be taught to take care of any wounds and cuts on their lower extremities, consequences of not wearing footwear and wearing ill-fitting shoes, precautions while cutting nails, using hot water, and use of moisturizers. Patients should also be educated about the outcomes of "no foot care", self-examination, hygiene, and exercise. ${ }^{54}$

Changing the footwear regularly also helps in healing the ulcers and reduces the frequency of recurrence of ulcers. As per a prospective observational study conducted by Saleem et al in Saudi Arabia, 79\% patients who changed their footwear showed earlier healing than those who did not change their footwear. Use of medicated shoes is also beneficial. ${ }^{55}$

\section{Autoamputation in diabetic dry gangrene}

As mentioned in the previous section, autoamputation is usually practiced either in ischemic, dry, and non-infected gangrene or in cases where surgery is not recommended. Dry gangrene always has a potential to become infected due to moisture absorption from the surroundings. Thus, waiting for autoamputation may lead to worsening of the condition. Also, a long wait enhances the duration of pain and discomfort and reduces the patient's overall QoL. ${ }^{9,56}$

\section{Role of surgical amputation in dry gangrene}

Due to chronic ischemia, the tissue becomes numb, dry, wrinkled, and dead. Thus, in case of necrotic tissues or dry gangrene, revascularization does not show any benefits. ${ }^{57}$ As per various reported cases, it has been observed that the surgical amputation is helpful in quick recovery and in reducing the discomfort and health complications associated with dry gangrene. After the surgical removal of gangrene foot or toe, a course of antibiotics while wound is healing (for quick healing without infections) should be considered important.

In a case series, an 82-year-old female patient preferred surgical amputation over autoamputation to achieve quick recovery. Later, the patient received physical therapy and could successfully walk with the help of prosthetic shoe. In another case of a male diabetic patient from this case series report, the toe with osteomyelitis and necrosis was surgically amputated. The patient successfully recovered and healed with a course of antibiotics. The same case series reported a case of a 45-year-old diabetic female patient with dry gangrene in toes, who was made to undergo transmetatarsal amputation. After surgery, the patient successfully healed and walked with a special shoe. ${ }^{50}$

The process of elective limb amputation should be individualized depending on the disease condition. It is well justified in patients with severe diabetic foot gangrene. As per a prospective study conducted by Elsharawy in Saudi Arabia, elective transtarsal amputations can reduce the chances of total limb amputation and improve ambulation rates. Surgical transtarsal amputation is known to improve mobility in 94\%-98\% patients as compared to patients $(50 \%-55 \%)$ undergoing below-knee amputation. In this study, overall functional ambulation was improved in 67\% (20/30) patients in a span of 6 months without any further equinus deformity. The number of limb amputations also reduced with only two-thirds of the limbs undergoing salvaging. ${ }^{58}$

Petkov et al had put more light on the benefits of surgical amputation in managing diabetic foot gangrene progression. Planned surgical treatments are reported to be directly proportional to decrease in total foot amputations. As per their study, surgical removal of the affected toes reduced complete foot amputation by $5.7 \% .^{59}$ 


\section{Conclusion}

In conclusion, proper education and management of patients who are at high risk of dry gangrene may reduce the total disease burden and associated complications in Arab countries. Although autoamputation is very commonly practiced over surgical amputation, in extreme cases, delay in management of the condition or a long wait for autoamputation may worsen the progression of dry gangrene and the QoL. On the other hand, surgical or elective amputation may relieve the patients in lesser time with lesser duration of painful phase and better outcomes. Surgical amputation also positively impacts the patient's functional ambulation with lesser risk of further limb deterioration and improved survival rates. Hence, the concept of autoamputation should be individualized and practiced with caution.

\section{Disclosure}

The author reports no conflicts of interest in this work.

\section{References}

1. IDF.org. Brussels, Belgium: International Diabetes Federation, IDF Diabetes Atlas 2011, 5th Addition. Available from: https:/www.idf. org/e-library/epidemiology-research/diabetes-atlas/20-atlas-5th-edition. html. Accessed October 26, 2017.

2. Who.int. Geneva, Switzerland: World Health Organization 2016, Global Reports on Diabetes. Available from: http://apps.who.int/iris/bitstr eam/10665/204871/1/9789241565257_eng.pdf. Accessed October 26, 2017.

3. Abuyassin B, Laher I. Diabetes epidemic sweeping the Arab world. World J Diabetes. 2016;7(8):165-174.

4. Ang CL, Lim YJ. Recurrent admissions for diabetic foot complications. Malays Orthop J. 2013;7(3):21-26.

5. Badri MM, Tashkandi WA, Aldaqal SM, Nawawi AA, Kensarah AM, Alzahrani HA. Extremities amputations in King Abdulaziz University Hospital (2005-2009). JKAU Med Sci. 2011;18(2):13-25.

6. Alzahrani HA. Diabetes-related lower extremities amputations in Saudi Arabia: the magnitude of the problem. Ann Vasc Dis. 2012;5(2): 151-156.

7. Tabur S, Eren MA, Çelik Y, et al. The major predictors of amputation and length of stay in diabetic patients with acute foot ulceration. Wien Klin Wochenschr. 2015;127(1-2):45-50.

8. Al-Kaabi JM, Al Maskari F, Cragg P, Afandi B, Souid AK. Illiteracy and diabetic foot complications. Prim Care Diabetes. 2015;9(6):465-472.

9. Fikri R, Bicknell CD, Bloomfield LM, et al. Awaiting autoamputation: a primary management strategy for toe gangrene in diabetic foot disease. Diabetes Care. 2011;34(8):e134.

10. Chopra BK. Health related quality of life studies in Indian patients after limb salvage surgery: need of the hour. Med JArmed Forces India. 2013;69(3):209-210.

11. NHP.gov.in. India: National Health Portal (NHP) 2015, Gangrene. Available from: https://www.nhp.gov.in/. Accessed October 26, 2017.

12. Armstrong DG, Boulton AJM, Bus SA. Diabetic foot ulcers and their recurrence. $N$ Engl J Med. 2017;376:2367-2375.

13. Matsuura GT, Barg N. Update on the antimicrobial management of foot infections in patients with diabetes. Clin Diabetes. 2013;31(2):59-65.

14. Nikolakopoulos KM, Papageorgopoulou CP, Papadoulas SI, Kakkos S Ntouvas I, Tsolakis IA. Wet gangrene and transmetatrsal amputation: how and why? Cardiol Res Cardiovasc Med. 2016;(2):1-3.
15. Ying Z, Zhang M, Yan S, Zhu Z. Gas gangrene in orthopaedic patients. Case Rep Orthop. 2013;2013:942076.

16. Badran M, Laher I. Type II diabetes mellitus in Arabic-speaking countries. Int J Endocrinol. 2012;2012:902873.

17. Al-Rubeaan K, Al Derwish M, Ouizi S, et al. Diabetic foot complications and their risk factors from a large retrospective cohort study. PLoS One. 2015;10(5):e0124446.

18. Al-Hariri MT, Al-Enazi AS, Alshammari DM, Bahamdan AS, AlKhtani SM, Al-Abdulwahab AA. Descriptive study on the knowledge, attitudes and practices regarding the diabetic foot. J Taibah Univ Med Sci. 2017:12(6):492-496.

19. Nemcová J, Hlinková E. The efficacy of diabetic foot care education. $J$ Clin Nurs. 2014;23(5-6):877-882.

20. Odhayani AA, Tayel SS, Al-Madi F. Foot care practices of diabetic patients in Saudi Arabia. Saudi J Biol Sci. 2017;24(7):1667-1671.

21. Blauw LL, Aziz NA, Tannemaat MR, et al. Diabetes incidence and glucose intolerance prevalence increase with higher outdoor temperature. BMJ Open Diabetes Res Care. 2017;5(1):e000317.

22. Abolghasemi R, Sedaghat M. The patient's attitude toward type 2 diabetes mellitus, a qualitative study. J Relig Health. 2015;54(4): 1191-1205.

23. Ibrahim M, Abu Al Magd M, Annabi FA, et al. Recommendations for management of diabetes during Ramadan: update 2015. BMJ Open Diabetes Res Care. 2015;3(1):e00108.

24. Rodrigues J, Mitta N. Diabetic Foot and Gangrene, Gangrene - Current Concepts and Management Options. Alexander Vitin, editor. InTech, Available from: https://www.intechopen.com/books/gangrenecurrent-concepts-and-management-options/diabetic-foot-and-gangrene Accessed October 26, 2017.

25. AlGoblan A, Alrasheedi I, Basheir O, Haider K. Prediction of diabetic foot ulcer healing in type 2 diabetic subjects using routine clinical and laboratory parameters. Res Rep Endocr Disord. 2016;6:11-16.

26. Schaberg DS, Norwood JM. Case study: infections in diabetes mellitus. Diabetes Spectr. 2002;15(1):37-40.

27. European Stroke Organization, Tendera M, Aboyans V, et al; ESC Committee for Practice Guidelines. ESC guidelines on the diagnosis and treatment of peripheral artery diseases: document covering atherosclerotic disease of extracranial carotid and vertebral, mesenteric, renal, upper and lower extremity arteries. The task force on the diagnosis and treatment of peripheral artery diseases of the European Society of Cardiology (ESC). Ear Heart J. 2011;32(22):2851-2906.

28. Clement SH, Kumar MA, Ramchander S. Clinical study of peripheral arterial occlusive disease of lower extremities. Int Surg J. 2017;4(1):403-407.

29. Kaushik R, Sree BS, Attri AK. Spontaneous auto-amputation of the foot in a case of diabetes, atherosclerosis and gangrene. $J$ Indian Med Assoc. 2002;100(9):573-574.

30. Weledji EP, Fokam P. Treatment of the diabetic foot - to amputate or not? BMC Surg. 2014;14:83.

31. IDF.org. Brussels, Belgium. IDF Diabetes Atlas. International Diabetes Federation. 4th edition: 1-104. Available from: https://www.idf.org/elibrary/epidemiology-research/diabetes-atlas/21-atlas-4th-edition.html. Accessed October 26, 2017.

32. Ast.org. Caudell BS. Gangrene: Recognizing and treating cellular necrosis. Association of Surgical Technologists; The Surgical Technologist; December 2008:547-555.Available from: http://www.ast.org/pdf/300. pdf. Accessed October 26, 2017.

33. Hilton JR, Williams DT, Beuker B, Miller DR, Harding KG. Wound dressings in diabetic foot disease. Clin Infect Dis. 2004;39(2):S100-S103.

34. Rivolta N, Piffaretti G, Tozzi M, et al. Two-stage treatment for diabetic foot: surgical peripheral revascularization and minor amputation in day-surgery admission. Int J Surg. 2008;6(1):S75-S77.

35. Kavitha KV, Tiwari S, Purandare VB, Khedkar S, Bhosale SS, Unnikrishnan AG. Choice of wound care in diabetic foot ulcer: a practical approach. World J Diabetes. 2014;5(4):546-556.

36. Tripathi KD, Essentials of Medical Pharmacology. 7th ed. New Delhi: Jaypee Brothers Medical Publishers (P) Ltd; 2003. 
37. NHS.org. Leicester: Modha D, Bukhari S, Swann A, Kong MF, Dawson K. Antimicrobial Guidelines for the Empirical Management of Diabetic Foot Infections. University Hospitals of Leicester, NHS Trust; 2007. Available from: http://www.leicestershirediabetes.org.uk/uploads/123/ documents/UHL\%20Antimicrobial\%20Guidelines\%20Diabetic\%20 Foot\%20Infections.pdf. Accessed October 26, 2017.

38. Drugbank.ca. Drug bank, Canadian Institutes of Health Research and Alberta Innovates - Health Solutions, and by the Metabolomics Innovation Centre (TMIC). Available from: https://www.metabolomicscentre. ca/equipment. Accessed October 26, 2017.

39. Salahuddin O, Azhar M, Imtiaz A, Latif M. A developing world experience with distal foot amputations for diabetic limb salvage. Diabet Foot Ankle. 2013;4:10.

40. Qari FA, Akbar D. Diabetic foot: presentation and treatment. Saudi Med J. 2000;21(5):443-446.

41. Bailey CJ. The current drug treatment landscape for diabetes and perspectives for the future. Clin Pharmacol Ther. 2015;98(2):170-184.

42. Schellhase KG, Koepsell TD, Weiss NS. Glycemic control and the risk of multiple microvascular diabetic complications. Fam Med. 2005;37(2):125-130.

43. Woelk CJ. Management of critical limb ischemia. Can Fam Physician. 2012;58(9):960-963.

44. Miller SR, Littenberg B, MacLean CD. Prevalence of antiplatelet therapy in patients with diabetes. Cardiovasc Diabetol. 2005;4:18.

45. Gerhard-Herman MD, Gornik HL, Barrett C, et al. 2016 AHA/ACC guideline on the management of patients with lower extremity peripheral artery disease: executive summary: a report of the American College of Cardiology/American Heart Association task force on clinical practice guidelines. J Am Coll Cardiol. 2017;69(11):1465-1508.

46. Salvo SG. Mosby's Pathology for Massage Therapists. 4th ed. St Louis, MO, USA: Elsevier; 2018.
47. Memon H, Rahimoon AG, Yousafani A. Frequency and outcome of dyslipidaemia in diabetic foot patients with type-II diabetes mellitus. Indo Am J Pharm Sci. 2017;4(10):3470-3475.

48. Eliasson B, Svensson AM, Miftaraj M, et al. Clinical use and effectiveness of lipid lowering therapies in diabetes mellitus-an observational study from the Swedish national diabetes register. PLoS One. 2011;6(4): e18744.

49. John RP. A study to assess the knowledge regarding foot care among diabetic patients attending OPD'S at selected hospitals of Lucknow. SSRG Int J Nurs Health Sci. 2017;3(2):7-9.

50. Issa AA, Newman M, Simman R. Toe necrosis, etiologies and management, a case series. J Am Coll Clin Wound Spec. 2014;5(2):26-35.

51. Vascular.org. Chicago, IL, USA: Vascular tests, Society for Vascular Surgery. Available from: https://vascular.org/patient-resources/vasculartests. Accessed March 14, 2018.

52. Castronuovo JJ Jr, Adera HM, Smiell JM, Price RM. Skin perfusion pressure measurement is valuable in the diagnosis of critical limb ischemia. J Vasc Surg. 1997;26(4):629-637.

53. Alzahrani H, BedirY, Al-Hayani A. Efficacy of shellac, a natural product, for the prevention of wet gangrene. J Into Med Res. 2013;41(3):795-803.

54. Bisht GS. Management diabetic foot $\&$ diabetic foot care education-A case report. Fam Med Media Sci Res. 2013;2(2):109.

55. Saleem SM, Naeemi AA, Tareen MK. An experience of diabetic foot in kingdom of Saudi Arabia. Pak J Med Sci. 2017;33(3):517-518.

56. Mat Saad AZ, Khoo TL, Halim AS. Wound bed preparation for chronic diabetic foot ulcers. ISRN Endocrinol. 2013;2013:608313.

57. Brearley S. Acute leg ischaemia. Br Med J. 2013;346:f2681.

58. Elsharawy MA. Outcome of midfoot amputations in diabetic gangrene. Ann Vasc Surg. 2011;25(6):778-782.

59. Petkov R, Gavrailov M, Gavrailov N, et al. [Surgical treatment of the diabetic septic foot]. Khirurgiia (Sofiia). 2004;60(2):22-24. Bulgarian.

\section{Publish your work in this journal}

Diabetes, Metabolic Syndrome and Obesity: Targets and Therapy is an international, peer-reviewed open-access journal committed to the rapid publication of the latest laboratory and clinical findings in the fields of diabetes, metabolic syndrome and obesity research. Original research, review, case reports, hypothesis formation, expert opinion and commentaries are all considered for publication. The manuscript management system is completely online and includes a very quick and fair peer-review system, which is all easy to use. Visit http://www.dovepress.com/testimonials.php to read real quotes from published authors. 